\title{
Decreased Insulin Activation of Glycogen Synthase in Skeletal Muscles in Young Nonobese Caucasian First-Degree Relatives of Patients with Non-Insulin-dependent Diabetes Mellitus
}

\author{
Allan Vaag, Jan Erik Henriksen, and Henning Beck-Nielsen \\ Diabetes Research Center, Odense University, Department of Endocrinology and Internal Medicine M, Odense University Hospital, \\ Odense; and Hvidöre Hospital, Klampenborg, Denmark
}

\begin{abstract}
Insulin resistance in non-insulin-dependent diabetes is associated with a defective insulin activation of the enzyme glycogen synthase in skeletal muscles. To investigate whether this may be a primary defect, we studied 20 young $(25 \pm 1$ yr) Caucasian first-degree relatives (children) of patients with non-insulindependent diabetes, and 20 matched controls without a family history of diabetes. Relatives and controls had a normal oral glucose tolerance, and were studied by means of the euglycemic hyperinsulinemic clamp technique, which included performance of indirect calorimetry and muscle biopsies. Insulin-stimulated glucose disposal was decreased in the relatives $(9.2 \pm 0.6$ vs $11.5 \pm 0.5 \mathrm{mg} / \mathrm{kg}$ fat-free mass per (FFM) $\mathrm{min}, P$ $<0.02$ ), and was due to a decreased rate of insulin-stimulated nonoxidative glucose metabolism $(5.0 \pm 0.5 \mathrm{vs} 7.5 \pm 0.4 \mathrm{mg} / \mathrm{kg}$ fat-free mass per min, $P<0.001$ ). The insulin-stimulated, fractional glycogen synthase activity $(0.1 / 10 \mathrm{mmol}$ liter glucose-6-phosphate) was decreased in the relatives $(46.9 \pm 2.3$ vs $56.4 \pm 3.2 \%, P<0.01$, and there was a significant correlation between insulin-stimulated, fractional glycogen synthase activity and nonoxidative glucose metabolism in relatives $(r=0.76$, $P<0.001)$ and controls $(r=0.63, P<0.01)$. Furthermore, the insulin-stimulated increase in muscle glycogen content over basal values was lower in the relatives $(13 \pm 25 \mathrm{vs} 46 \pm 9 \mathrm{mmol} / \mathrm{kg}$ dry wt, $P=0.05$ ). We conclude that the defect in insulin activation of muscle glycogen synthase may be a primary, possibly genetically determined, defect that contributes to the development of non-insulin-dependent diabetes. (J. Clin. Invest. 1992. 89:782-788.) Key words: glycogen synthase • skeletal muscles • non-insulin-dependent diabetes mellitus • insulin resistance • relatives
\end{abstract}

\section{Introduction}

Decreased rates of glucose disposal in response to a euglycemic, intravenous insulin infusion, defined as insulin resistance, may play an important role in the pathophysiology of non-insulin-

Address correspondence and reprint requests to Dr. Allan Vaag, Department of Endocrinology and Internal Medicine M, Odense University Hospital, Sdr. Boulevard, DK-5000 Odense C, Denmark.

Received for publication 12 September 1991.

J. Clin. Invest.

(C) The American Society for Clinical Investigation, Inc.

0021-9738/92/03/0782/07 \$2.00

Volume 89, March 1992, 782-788 dependent diabetes mellitus (NIDDM) ${ }^{1}(1-4)$. The intracellular metabolic fate of glucose after passing the cell membrane is either through nonoxidative pathways, largely accounted for by storage of glucose as glycogen, or through oxidation of glucose in the Krebs cycle. The insulin resistance in NIDDM occurs in both oxidative and nonoxidative pathways, although the predominant defect is in nonoxidative glucose metabolism (3-8). The main site of the insulin resistance is considered to be in skeletal muscle $(3,5,9)$, and the reduced insulin-stimulated glucose disposal in NIDDM has been shown primarily to be due to decreased rates of muscle glucose storage as glycogen (9). The rate limiting key enzyme in this pathway is glycogen synthase $(10,11)$. Muscle glycogen synthase is dephosphorylated, and thus stimulated covalently by insulin $(11,12)$, and a close correlation between in vivo insulin-stimulated muscle glycogen synthase activity, and whole body nonoxidative glucose disposal has been demonstrated in normal Caucasian subjects $(4,5,11)$, in Caucasian patients with $\operatorname{NIDDM}(4,5)$, and in a mixture of American Pima Indians with and without NIDDM (13). In addition, a defect insulin activation of glycogen synthase in skeletal muscles has now become a well-established and consistent finding in $\operatorname{NIDDM}(4,5,14,15)$.

Recently, insulin resistance in the glucose storage pathway was demonstrated in obese "prediabetic" Pima Indians (16), and in middle-aged obese Caucasian glucose tolerant, first-degree relatives of patients with NIDDM (17). It was suggested that the insulin resistance could be a primary, and perhaps genetically determined, defect of nonoxidative glucose metabolism that leads to the development of NIDDM. In addition, the localization of this defect was inferred to be due to an impairment in activation by insulin of glycogen synthase in skeletal muscle $(16,17)$. In these studies, however, no direct evidence for a defect of this pathway in skeletal muscle was provided. Furthermore, the possibility that the defect of nonoxidative glucose metabolism in the prediabetic Pima Indians and in the Caucasian relatives was due to obesity itself, cannot be excluded. Thus, we recently demonstrated that obesity in nondiabetic Caucasian subjects is associated with insulin resistance in the nonoxidative glucose metabolism, and furthermore, with a decreased insulin activation of glycogen synthase in skeletal muscle (4).

Therefore, the aim of the present study was to measure in skeletal muscle the activation of glycogen synthase by insulin in nonobese, glucose-tolerant, Caucasian first-degree relatives of patients with NIDDM, a group known to be at risk for devel-

1. Abbreviations used in this paper: FFM, fat-free mass; G6P, glucose6-phosphate; HGO, hepatic glucose output; NEFA, nonesterified fatty acids; NIDDM, non-insulin-dependent diabetes mellitus, UDPG, uridine diphosphate glucose. 
oping NIDDM (18). Importantly, we elected to investigate relatives below the age of $30 \mathrm{yr}$, in order to establish whether a defect in nonoxidative glucose metabolism and/or in glycogen synthase activity in skeletal muscle is present several decades before a person is destined to develop NIDDM.

\section{Methods}

\section{Subjects}

Initially, 22 first-degree relatives (children) of patients with NIDDM were recruited to the study. These relatives were traced by questioning patients with verified NIDDM at the outpatient clinics at Hvidøre Hospital, and the Department of Endocrinology and Internal Medicine at Odense University Hospital. Subjects who fulfilled the inclusion criteria and who agreed to participate were included consecutively into the study. Inclusion criteria were the presence of at least two first-degree relatives with NIDDM, or alternatively, the presence of one first-degree relative and at least two second-degree relatives with NIDDM. All relatives who participated in the study had at least one parent with verified NIDDM. Furthermore, only relatives between the age of 18 and $30 \mathrm{yr}$, and with normal oral glucose tolerance tests, were included in the study. Thus, two relatives were excluded from the study after performing the oral glucose tolerance test. One of these relatives had previously unrecognized NIDDM, and the other had impaired glucose tolerance. The 20 relatives who participated in the study were compared with 20 control subjects with normal oral glucose tolerance, and without any family history of NIDDM. Relatives and control subjects were carefully matched according to age, sex, and body mass index (Table I). None of the subjects had clinical evidence of endocrine, cardiac, hepatic, or renal disease, and none of the subjects were taking any medication known to influence glucose metabolism. The subjects were not undertaking arduous exercise, and all subjects were instructed to avoid excessive physical exercise at least $2 \mathrm{~d}$ before clamp studies. All studies in relatives and controls were run in parallel to eliminate time and season variation in any of the measurements. Informed consent was obtained. The study was approved by the regional ethical committee, and the procedure was performed according to the principles of the Helsinki Declaration.

Table I. Clinical Characteristics of First-Degree Relatives of Patients with NIDDM, and Control Subjects Without a Family History of NIDDM

\begin{tabular}{|c|c|c|}
\hline & $\begin{array}{l}\text { Control } \\
\text { subjects }\end{array}$ & Relatives \\
\hline Females/males & $10 / 10$ & $10 / 10$ \\
\hline Age $(y r)$ & $24.5 \pm 0.6$ & $25.3 \pm 0.6$ \\
\hline \multicolumn{3}{|l|}{ Body mass index } \\
\hline$\left(\mathrm{kg} / \mathrm{m}^{2}\right)$ & $23.6 \pm 0.5$ & $23.8 \pm 0.6$ \\
\hline Weight $(k g)$ & $72.6 \pm 2.3$ & $72.8 \pm 2.9$ \\
\hline Height $(m)$ & $1.75 \pm 0.02$ & $1.74 \pm 0.02$ \\
\hline Fat free mass $(F F M, k g)$ & $56.3 \pm 2.7$ & $54.0 \pm 2.5$ \\
\hline $\begin{array}{l}\text { Fasting plasma glucose } \\
\quad(\mathrm{mmol} / \text { liter })\end{array}$ & $5.2 \pm 0.1$ & $5.3 \pm 0.1$ \\
\hline $\begin{array}{l}\text { Fasting plasma insulin } \\
(\text { nmol/liter })\end{array}$ & $0.04 \pm 0.01$ & $0.07 \pm 0.01^{*}$ \\
\hline $\begin{array}{l}\text { Fasting plasma C-peptide } \\
\text { (nmol/liter) }\end{array}$ & $0.50 \pm 0.04$ & $0.66 \pm 0.04^{*}$ \\
\hline Glycosylated hemoglobin (\%) & $5.2 \pm 0.1$ & $5.2 \pm 0.1$ \\
\hline
\end{tabular}

Fasting glucose, insulin, and C-peptide concentrations are all the means of four determinations. Mean \pm SEM. ${ }^{*} P<0.01$.

\section{In vivo methods}

Oral glucose-tolerance test. This test was performed on a separate day before clamp studies in order to ensure normal glucose tolerance in all study subjects. After a 10-h overnight fast, the subjects were given a 75-g oral glucose load. Venous blood samples were taken before the glucose was administered, every 15 min during the first hour after glucose administration, and finally every $30 \mathrm{~min}$ from 1 to $4 \mathrm{hr}$ after glucose administration.

Euglycemic hyperinsulinemic clamp. Studies were started at 07.30 after a 10-h overnight fast. A polyethylene catheter was inserted into an antecubital vein for infusion of test substances. Another polyethylene catheter was inserted into a contralateral wrist vein for blood sampling. This hand was placed and maintained in a heated Plexiglas box to obtain arterialized venous blood (19). After a 120-min basal equilibration period for basal measurements (Fig. 1), insulin (Actrapid; NovoNordisk, Bagsvaerd, Denmark) was infused for $180 \mathrm{~min}$ at a constant rate of $40 \mathrm{mU} / \mathrm{m}^{2}$ per min in both relatives and control subjects. Plasma glucose concentration was maintained constant at euglycemia, using a variable glucose infusion ( $180 \mathrm{~g} /$ /iter $)$. Plasma glucose concentration was monitored in arterialized blood every 5-10 min using an automated glucose-oxidase method (Glucose Analyzer 2; Beckman Instruments, Inc., Fullerton, CA). Steady-state periods were defined as the last 30 min during basal measurements $(-30-0 \mathrm{~min})$, and the last $30 \mathrm{~min}$ during insulin-stimulated measurements (150-180 min).

Tritiated glucose. The glucose-clamp studies were combined with a primed continuous infusion of $\left.3{ }^{3} \mathrm{H}\right]$ glucose (New England Nuclear; Boston, MA)(Fig. 1). The radiochemical purity of the tracer was $100 \%$, as determined by HPLC. To ensure achievement of isotope equilibrium, the continuous infusion of $3\left[{ }^{3} \mathrm{H}\right]$ glucose $(0.22 \mu \mathrm{Ci} / \mathrm{min})$ was begun 90-120 min before measurements of glucose turnover were performed. Blood samples were drawn in fluoride-treated tubes every 10 min during basal ( $-30-0 \mathrm{~min}$ ) and insulin-stimulated (150-180 $\mathrm{min})$ steady-state periods for determination of plasma glucose and plasma $3\left[{ }^{3} \mathrm{H}\right]$ glucose activity. During the rest of the study period $(-120--30$ min and $0-150 \mathrm{~min}$ ), plasma glucose and $3\left[{ }^{3} \mathrm{H}\right]$ glucose activity was measured every $30 \mathrm{~min}$.

Indirect calorimetry. Indirect calorimetry was performed using a computerized, flowthrough canopy gas analyzer system (Deltatrac; Datex, Helsinki, Finland). Briefly, air was suctioned at a rate of 40 liter per min through a canopy placed over the head of the subject. Samples of inspired and expired air were analyzed for oxygen concentration, using a paramagnetic differential oxygen sensor, and were analysed for carbon dioxide using an infrared carbon dioxide sensor. Signals from the gas analyzers were processed by the computer, and oxygen consumption, and carbon dioxide production was calculated and recorded once a minute. After an equilibration period of $10 \mathrm{~min}$, the average gas exchange rates recorded over the two 30-min steady-state periods (Fig. 1) were used to calculate rates of glucose oxidation, lipid oxidation, and energy expenditure, as previously described $(20,21)$. The protein oxidation rate was estimated from urinary urea nitrogen excretion $(1 \mathrm{~g}$ nitrogen $=6.25 \mathrm{~g}$ protein) and corrected for changes in pool size (22).

Muscle biopsy. Muscle biopsies were performed using a modified Bergström needle (including suction) under local anesthesia. The biopsies were rapidly (within 10-15 s) frozen, and stored in liquid nitrogen for later analysis. Before the biochemical analysis, the muscle samples were freeze dried and dissected free of visible connective tissue, fat, and blood.

Calculations. During the steady-state periods, glucose turnover rates (hepatic glucose output [HGO] and total peripheral glucose disposal) were calculated at 10-min intervals using Steele's equations (23). In these calculations, the distribution volume of glucose was taken as $200 \mathrm{ml} / \mathrm{kg}$ body wt, and the pool fraction as $0.65(24)$. During the insulin infusion periods, negative rates of $\mathrm{HGO}$ were calculated in all subjects. Such underestimation of glucose turnover by the tracer method is largely accounted for by a model error emerging at high rates of glucose metabolism (25). We took the negative numbers to indicate a nil HGO. Thus, because HGO was negative during the insulin infusion 


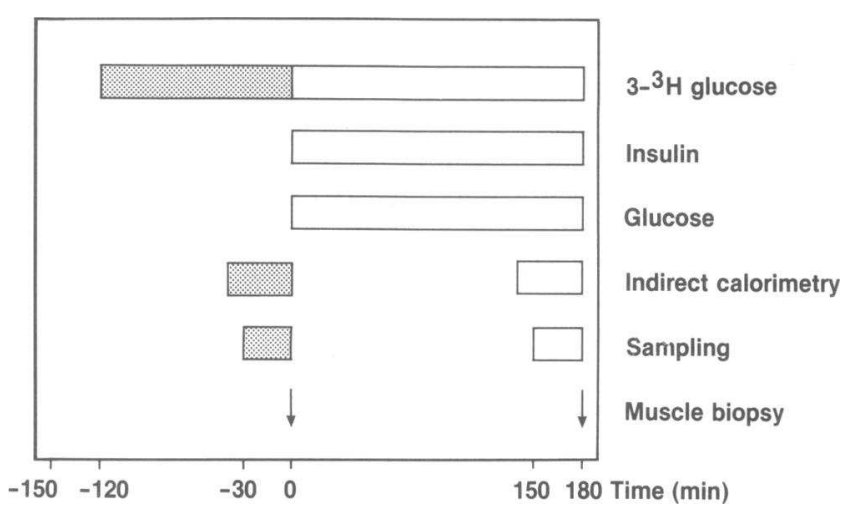

Figure 1. Experimental study design. Plasma glucose concentration was clamped at euglycemia in the study subjects. Each clamp study was preceded by a 120-min period for basal measurements (solid bars). Insulin was infused for $180 \mathrm{~min}$ at a rate of $40 \mathrm{mU} / \mathrm{m}^{2}$ per min. Steady-state measurements of glucose turnover were made, and indirect calorimetry was carried out during last $30 \mathrm{~min}$ of basal and clamp periods. During this time, plasma was analyzed for glucose, insulin, C-peptide, and NEFA. Muscle biopsies were taken from the vastus lateralis muscle in the basal state, and after $180 \mathrm{~min}$ insulin infusion.

in all of the study subjects, the infusion rate of exogenous glucose was used to estimate total peripheral glucose disposal. Nonoxidative glucose metabolism (glucose storage) was calculated as the difference between total body glucose utilization, and glucose oxidation, as determined by indirect calorimetry. The insulin sensitivity index was calculated as the measure of insulin action, as described by Bergman et al. (26). Glucose and lipid metabolism data were expressed as mg per $\mathrm{kg}$ fat-free mass (FFM) per min. Total body fat, and thus FFM, were measured using the bioimpedance method (27).

\section{In vitro methods}

Glycogen and metabolite concentrations in muscle biopsies. Glycogen was measured as glucose residues after hydrolysis of the muscle samples, in $1 \mathrm{M} \mathrm{HCl}$ at $100^{\circ} \mathrm{C}$ for $2 \mathrm{~h} \mathrm{(28).} \mathrm{Glucose} \mathrm{and} \mathrm{glucose} \mathrm{6-phos-}$ phate (G6P) were measured flurometrically on neutralized perchloric acid extracts (28). Intracellular concentrations of free glucose and G6P were calculated as millimoles per liter intracellular water, assuming an extracellular water content in the biopsies of 0.3 liter $/ \mathrm{kg}$ dry weight, and an intracellular water content of 2.8 liters/kg dry weight $(29,30)$. The intracellular concentrations of free glucose were corrected for extracellular concentrations using the above assumptions of intracellular and extracellular water content in the biopsies.

Glycogen synthase activity. Extraction of muscle samples and assays for glycogen synthase (GS) were performed as we previously described $(4,11)$, by a modification of the method of Thomas et al. (31). Glycogen synthase activity was assayed without adding G6P, in the presence of a near physiological concentration of G6P $(0.1 \mathrm{mmol} /$ liters), and in the presence of a high concentration of G6P $(10 \mathrm{mmol} /$ liters). The concentration of $10 \mathrm{mmol} /$ liters was used to determine maximal enzyme activity. The total concentration of uridine diphosphate glucose $\left(\left[{ }^{14} \mathrm{C}\right]\right.$ UDPG + cold UDPG) in the reaction mixture was $0.31 \mathrm{mM}$. Glycogen synthase activity was expressed as nanomoles of UDPG incorporated into glycogen per minute per milligram extract protein. Fractional velocities (FV) were calculated as the ratio between glycogen synthase activities assayed at $0 \mathrm{mM}$ G6P and $10 \mathrm{mM}$ G6P (FV 0.0), and at $0.1 \mathrm{mM} \mathrm{G6P}$ and $10 \mathrm{mM}$ G6P (FV 0.1). Protein content of the extracts was determined by the method of Lowry (32).

Analytical determinations. Glucose in plasma and urine was determined by a hexokinase method (33). Tritiated glucose activity was measured as described by Hother-Nielsen and Beck-Nielsen (34). Plasma insulin (35) and C-peptide (36) concentrations were measured with radioimmunological methods. Nonesterified fatty acids (NEFA) in plasma were determined by the method of Itaya and Michio (37). Plasma concentrations of glucose, insulin, and NEFA were measured every 10 min during both steady-state periods. Hemoglobin $\left(\mathrm{HbA}_{\mathrm{lc}}\right)$ was measured by isoelectric focusing (38) (normal range 4.1-6.1\%).

Statistical analysis. Nonparametric statistical methods (Wilcoxon test for paired data, Mann-Whitney test for unpaired data, and Spearman's rho [39] for correlation analysis) were employed in analysis of data. $P$ values $<0.05$ were considered significant. Data in text and figures are presented as the mean $\pm \mathrm{SE}$.

\section{Results}

The relatives had normal fasting plasma glucose concentrations and normal levels of glycosylated hemoglobin, whereas fasting concentrations of insulin and C-peptide (mean values of four determinations) were significantly elevated (Table I).

Plasma glucose and insulin concentrations during the oral glucose tolerance tests are given in Fig. 2. Despite only marginally elevated plasma glucose concentrations in the relatives, insulin concentrations in these subjects were clearly elevated during the oral glucose tolerance test (net area under curve $47.4 \pm 6.8$ vs $23.9 \pm 3.2 \mathrm{~min} \cdot \mathrm{nmol} /$ liters, $P<0.005$ ).

Plasma glucose, insulin, and NEFA concentrations during clamp studies are given in Table II. Plasma concentrations of glucose and insulin were constant during the predefined basal and insulin-stimulated steady-state periods, indicating that steady state was achieved during these two intervals. The mean coefficient of variation of plasma glucose concentrations during insulin infusions was $5 \%$ in both relatives and control studies. Plasma glucose concentrations were similar in relatives and control subjects during both basal and insulin-stimulated steady-state periods. Plasma insulin concentrations were elevated in the relatives in the basal state, but were similar during insulin infusion. Plasma NEFA concentrations were similar in
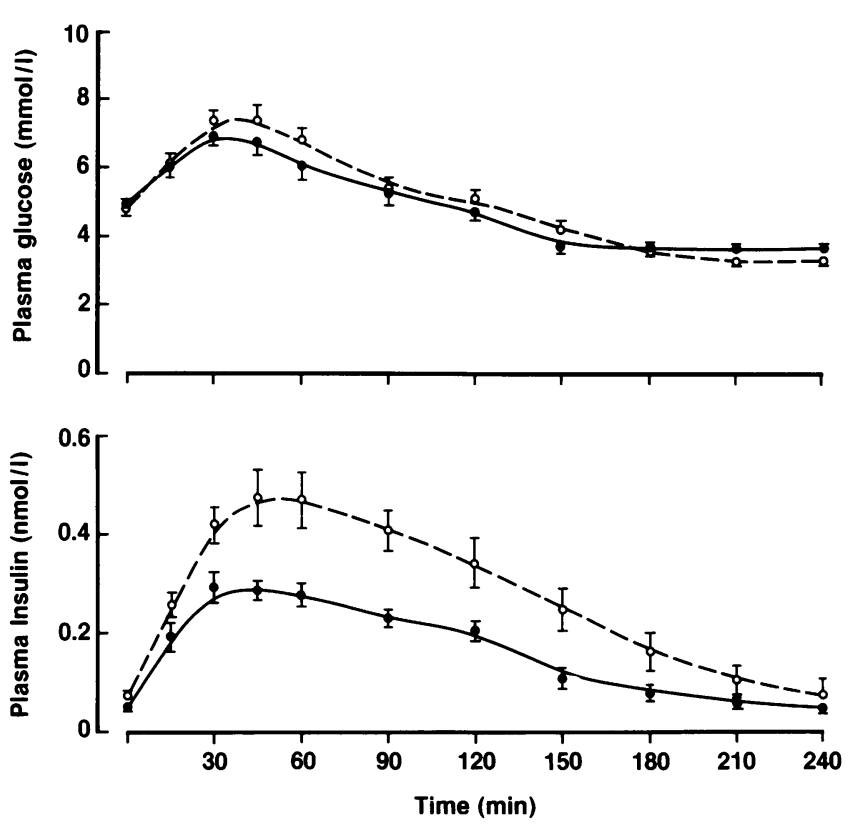

Figure 2. Plasma glucose and insulin concentrations during oral glucose-tolerance tests in 20 first-degree relatives of patients with NIDDM (open circles), and in 20 normal control subjects without a family history of NIDDM (closed circles). 
relatives and controls during both basal and insulin-stimulated steady-state periods.

Rates of insulin-stimulated glucose disposal were decreased in the relatives of patients with NIDDM $(11.5 \pm 0.5$ vs $9.2 \pm 0.6$ $\mathrm{mg} / \mathrm{kg}$ FFM per min, $P<0.02$, Fig. 3). Furthermore, the insulin sensitivity index was also significantly lower in the relatives $\left(0.52 \pm 0.05\right.$ vs $0.72 \pm 0.04\left[(\mathrm{liter})^{2} \cdot(\mathrm{kg} \mathrm{FFM})^{-2} \cdot(\mathrm{nmol}\right.$ insulin $)^{-2} \cdot(\min )^{-2}$ ], $\left.P<0.01\right)$.

Insulin-stimulated rates of glucose oxidation were similar in control subjects and relatives $(4.0 \pm 0.2 \mathrm{vs} 4.2 \pm 0.3 \mathrm{mg} / \mathrm{kg}$ FFM per min, NS), and thus the insulin resistance in the relatives was solely due to decreased rates of insulin-stimulated nonoxidative glucose disposal $(7.5 \pm 0.4$ vs $5.0 \pm 0.4 \mathrm{mg} / \mathrm{kg}$ FFM per min, $P<0.001$ ).

In the basal state, rates of total peripheral glucose disposal $(2.5 \pm 0.1$ vs $2.6 \pm 0.1 \mathrm{mg} / \mathrm{kg}$ FFM per min, NS), glucose oxidation (1.5 \pm 0.2 vs $1.8 \pm 0.1 \mathrm{mg} / \mathrm{kg}$ FFM per min, NS), and nonoxidative glucose disposal $(1.0 \pm 0.1$ vs $0.8 \pm 0.2 \mathrm{mg} / \mathrm{kg}$ FFM per min, NS) were similar in control subjects and relatives (Fig. 3).

HGO was the same in control subjects and relatives in the basal state ( $2.6 \pm 0.1 \mathrm{vs} 2.5 \pm 0.1 \mathrm{mg} / \mathrm{kg}$ FFM per min, NS), and was fully suppressed in both groups during insulin infusion $(-3.0 \pm 0.3 \mathrm{vs}-1.7 \pm 0.3 \mathrm{mg} / \mathrm{kg}$ FFM per min, NS).

Rates of lipid oxidation were similar in controls and relatives in the basal state $(1.4 \pm 0.1 \mathrm{vs} 1.3 \pm 0.1 \mathrm{mg} / \mathrm{kg}$ FFM per $\min , \mathrm{NS})$, and during insulin infusion $(0.6 \pm 0.1 \mathrm{vs} 0.5 \pm 0.1 \mathrm{mg} /$ $\mathrm{kg}$ FFM per min, NS). Furthermore, rates of whole body energy expenditure were identical in controls and relatives in the basal state ( $92 \pm 3$ vs $92 \pm 3 \mathrm{~J} / \mathrm{kg}$ FFM per $\mathrm{min}$ ), and during insulin infusion ( $93 \pm 3$ vs $96 \pm 3 \mathrm{~J} / \mathrm{kg}$ FFM per min).

The fractional skeletal muscle glycogen synthase activity at the physiological $0.1 \mathrm{mM}$ G6P concentration (FV 0.1) was significantly decreased in the relatives during insulin infusion (Table III). In addition, the insulin-stimulated increments in fractional muscle glycogen synthase activities over basal values were significantly lower in the relatives compared to the controls, when measured both without G6P (FV 0.0), and in the presence of the physiological G6P concentration (FV 0.1), (Table III). Insulin-stimulated increments in fractional glycogen synthase activities at $0.1 \mathrm{mmol} /$ liter G6P (FV 0.1) correlated significantly with insulin-stimulated increments in whole body

Table II. Plasma Glucose, Insulin, and Nonesterified Fatty Acid during Clamp Studies

\begin{tabular}{lcc}
\hline & $\begin{array}{l}\text { Control } \\
\text { subjects }\end{array}$ & Relatives \\
\hline $\begin{array}{l}\text { Glucose (mmol/liter) } \\
\text { Basal }\end{array}$ & $5.2 \pm 0.1$ & \\
Insulin & $5.3 \pm 0.1$ & $5.3 \pm 0.1$ \\
Insulin (nmol/liter) & & $5.3 \pm 0.1$ \\
Basal & $0.04 \pm 0.01$ & \\
Insulin & $0.42 \pm 0.02$ & $0.07 \pm 0.01^{*}$ \\
NEFA (mmol/liter) & & $0.47 \pm 0.05$ \\
Basal & $0.62 \pm 0.06$ & \\
Insulin & $0.05 \pm 0.01$ & $0.57 \pm 0.06$ \\
& & $0.05 \pm 0.01$ \\
\hline
\end{tabular}

Plasma concentrations are the means of four determinations in each subject during basal and insulin-stimulated $\left(3 \mathrm{~h}, 40 \mathrm{mU} / \mathrm{m}^{2}\right.$ per min) steady-state periods. Mean \pm SEM. ${ }^{*} P<0.01$ vs control subjects.

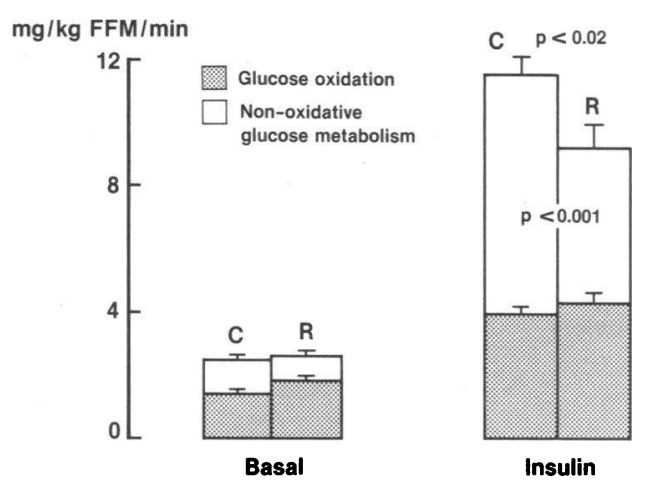

Figure 3. Rates of total body glucose disposal, glucose oxidation, and nonoxidative glucose metabolism in the basal postprandial state, and during insulin infusion $\left(3 \mathrm{~h}, 40 \mathrm{mU} / \mathrm{m}_{2}\right.$ per $\mathrm{min}$ ) in 20 first-degree relatives of patients with $\operatorname{NIDDM}(R)$, and 20 control subjects without a family history of $\operatorname{NIDDM}(C)$.

nonoxidative glucose metabolism, in both controls and relatives $(r=0.63, P<0.005$ and $r=0.76, P<0.0005$, respectively, Fig. 4).

The insulin-stimulated increase in muscle glycogen content over basal values was significantly lower in the relatives (Table IV). Intracellular concentrations of free glucose and G6P were unchanged in both groups during insulin infusion, and were similar in control subjects and relatives (Table IV).

\section{Discussion}

The present study demonstrates that insulin resistance is present in young nonobese Caucasian persons with a known increased risk for developing NIDDM decades before they are believed to contract the disease. The insulin resistance is located in the nonoxidative glucose metabolic pathway, and is closeıy correlated with a defect in insulin activation of muscle glycogen synthase. The decreased storage of glucose as muscle glycogen in response to the physiological insulin infusion provides further and direct evidence for a defect in this pathway in the first-degree relatives of patients with NIDDM.

Several lines of evidence indicate that genetic factors contribute to the development of NIDDM $(18,40-42)$. Thus, twin studies have demonstrated concordance rates of NIDDM in identical twins $>60 \%(41,42)$. Furthermore it was recently demonstrated in a prospective study that offsprings of two parents with NIDDM (first-degree relatives) have eight times the general population risk for development of NIDDM (18). American Pima Indians are an ethnic population also at high risk for NIDDM. Previous studies in nondiabetic Pima indians have shown that in vivo insulin action is a familial characteristic independent of age, sex, degree of obesity, and physical fitness (43). Longitudinal studies in Pima indians (16) and in rhesus monkeys (44) have demonstrated that insulin resistance precedes the development of NIDDM. In addition, the recent prospective study of children of two diabetic parents demonstrated that a slow glucose-removal rate was associated with hyperinsulinemia, implying insulin resistance, and preceded the development of NIDDM in these subjects(18). Insulin resistance in the nonoxidative pathway has been demonstrated in obese prediabetic Pima Indians (16), in obese and middle-aged, 
Table III. Activities of Skeletal Muscle Glycogen Synthase in 20 First-Degree Relatives of Patients with NIDDM, and in 20 Control Subjects without a Family History of NIDDM

\begin{tabular}{|c|c|c|c|c|}
\hline & \multicolumn{2}{|c|}{ Control subjects } & \multicolumn{2}{|c|}{ Relatives } \\
\hline & Basal & Insulin & Basal & Insulin \\
\hline $0.0 \mathrm{G} 6 \mathrm{P}(\mathrm{mmol})$ & $0.47 \pm 0.16$ & $1.00 \pm 0.25^{*}$ & $0.40 \pm 0.76$ & $0.83 \pm 0.17^{*}$ \\
\hline $0.1 \mathrm{G} 6 \mathrm{P}(\mathrm{mmol})$ & $2.25 \pm 0.51$ & $3.35 \pm 0.45^{*}$ & $1.85 \pm 0.24$ & $2.98 \pm 0.31^{*}$ \\
\hline $10 \mathrm{G} 6 \mathrm{P}(\mathrm{mmol})$ & $6.39 \pm 0.89$ & $5.90 \pm 0.55$ & $6.28 \pm 0.58$ & $6.38 \pm 0.51$ \\
\hline FV 0.0 & $6.3 \pm 1.4$ & $16.3 \pm 2.0^{*}$ & $5.9 \pm 0.9$ & $12.3 \pm 1.6^{*}$ \\
\hline FV 0.1 & $32.8 \pm 2.9$ & $56.4 \pm 3.2^{*}$ & $28.9 \pm 2.3$ & $46.9 \pm 2.3^{\ddagger *}$ \\
\hline$\Delta \mathrm{FV} 0.0$ & \multicolumn{2}{|c|}{$9.9 \pm 1.1$} & \multicolumn{2}{|c|}{$6.3 \pm 0.8^{8}$} \\
\hline$\Delta F V 0.1$ & \multicolumn{2}{|c|}{$23.5 \pm 1.6$} & \multicolumn{2}{|c|}{$18.0 \pm 1.5^{\ddagger}$} \\
\hline
\end{tabular}

Mean \pm SEM. ${ }^{*} P<0.01$ vs basal values; ${ }^{\ddagger} P<0.01$ vs control subjects; and ${ }^{\S} P<0.05$ vs control subjects. Biopsies were taken from the vastus lateralis muscle in the basal post absorptive state and after $3 \mathrm{~h}$ insulin infusion $\left(40 \mathrm{mU} / \mathrm{m}^{2}\right.$ per min). Glycogen synthase activities are given as UDP-glucose incorporated into glycogen per extract protein per min. Glycogen synthase activities were measured in the absence of its allosteric modulator glucose-6-phosphate $(0.0 \mathrm{mmol} /$ liter G6P), in the presence of a physiologic G6P concentration $(0.1 \mathrm{mmol} /$ liter $)$, and in the presence of a maximal stimulatory G6P concentration (10 mmol/liter). FV are given in percentages. $\triangle \mathrm{FV}$ values are insulin-stimulated increments in fractional velocities over basal values.

glucose-tolerant, Caucasian first-degree relatives of patients with NIDDM (17), and was demonstrated in the present study in young and carefully weight and sex matched nonobese glucose-tolerant Caucasian first-degree relatives of patients with NIDDM. Thus, these data taken together indicate that a familiarly and perhaps genetically determined insulin resistance in the glucose storage pathway may precede the development of frank NIDDM, and thus may be involved in causing the disease. Importantly, we demonstrated in the present study that the biochemical defect responsible for the defect of insulin action in these young Caucasian relatives with increased risk for development of NIDDM was a defect of insulin activation of the enzyme glycogen synthase in skeletal muscle, which was furthermore associated with a decreased increment in skeletal muscle glycogen content in response to the physiological insu-

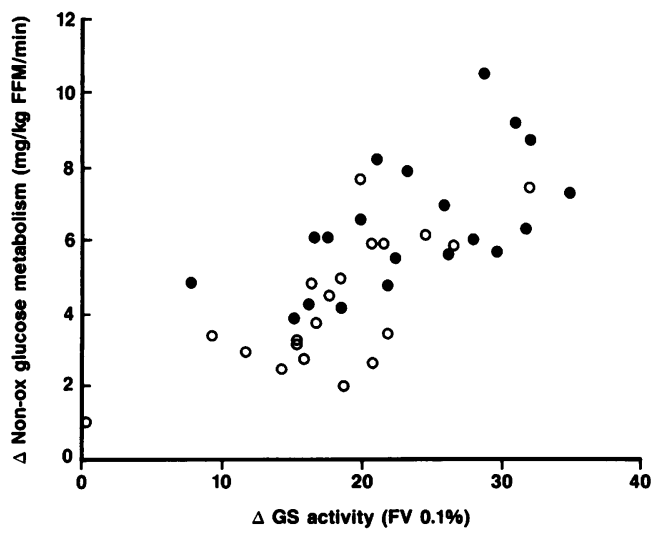

Figure 4. Relationship between increase over basal values of muscle glycogen synthase activities (FV at $0.1 \mathrm{mM} \mathrm{G6P)}$ ) and whole body nonoxidative glucose metabolism during insulin infusion $(3 \mathrm{~h}, 40$ $\mathrm{mU} / \mathrm{m}^{2}$ per $\mathrm{min}$ ) in 20 first-degree relatives of patients with NIDDM (open circles; $r=0.76, P<0.0005$ ) and in 20 normal control subjects without a family history of NIDDM (closed circles; $r=0.63, P$ $<0.005$ ). lin infusion. Therefore, the defective insulin activation of glycogen synthase may also be an inherited defect involved in the emergence of NIDDM.

Patients with overt NIDDM often have elevated fasting and postprandial plasma nonesterified fatty acid concentrations $(45,46)$. Through operation of the glucose-fatty acid cycle (47), it has been suggested that the impaired glucose utilization (insulin resistance) in NIDDM may be secondary to an enhanced rate of oxidation of lipids (48). In support of this hypothesis, we recently demonstrated that acute administration of the antilipolytic nicotinic acid analogue Acipimox improved the insulin action in NIDDM $\sim 30 \%$ by improving both the insulin-stimulated oxidative and nonoxidative glucose metabolism (49). The normal basal and insulin-stimulated NEFA levels, and the lipid oxidation rates observed in the relatives in the present study, are in accordance with the findings of Eriksson et al. in

Table IV. Intracellular Concentrations of Free Glucose, Glucose6-Phosphate (G6P), and Glycogen in Skeletal Muscles in 20 First Degree Relatives of Patients with NIDDM and in 20 Control Subjects without a Family History of NIDDM

\begin{tabular}{lcclcc}
\hline & \multicolumn{2}{c}{ Control subjects } & & \multicolumn{2}{c}{ Relatives } \\
\cline { 2 - 3 } \cline { 5 - 6 } \cline { 5 - 6 } & Basal & Insulin & & Basal & Insulin \\
\hline Glucose & $0.07 \pm 0.04$ & $0.01 \pm 0.06$ & & $0.05 \pm 0.04$ & $-0.07 \pm 0.05$ \\
G6P & $0.10 \pm 0.01$ & $0.11 \pm 0.02$ & & $0.11 \pm 0.02$ & $0.10 \pm 0.02$ \\
Glycogen & $416 \pm 20$ & $462 \pm 20^{*}$ & & $434 \pm 20$ & $447 \pm 31$ \\
DGlycogen & \multicolumn{2}{c}{$46 \pm 9$} & & \multicolumn{2}{c}{$13 \pm 25^{\ddagger}$}
\end{tabular}

Mean \pm SEM. ${ }^{*} P<0.02$ vs basal levels. ${ }^{\ddagger} P=0.05$ vs controls. Concentrations of free glucose and G6P are given as mmol/liter intracellular water, assuming an extracellular water content in muscle biopsies of 0.3 liter $/ \mathrm{kg}$ dry weight, and an intracellular water content of $2.8 \mathrm{liter} / \mathrm{kg}$ dry weight. Muscle glycogen content is given as $\mathrm{mmol} /$ kg dry weight. $\Delta$ Glycogen are insulin-stimulated increments in muscle glycogen over basal content. 
obese relatives (17), indicating that the insulin resistance in the relatives of patients with NIDDM may not be secondary to any abnormalities in the lipid metabolism. This may also suggest that the insulin resistance in overt NIDDM, apart from having a "metabolic" component secondary to an enhanced lipid oxidation, may have a primary, and perhaps genetically determined, component.

We previously found that insulin was unable to significantly stimulate the activity of muscle glycogen synthase in newly presenting obese patients with NIDDM (4). Given the fact that insulin was able to stimulate the activity of glycogen synthase in all but one of the relatives (Fig. 4), and furthermore, that there was considerable overlap of the insulin-stimulated nonoxidative glucose metabolism and activation of glycogen synthase between the groups of relatives and controls (Fig. 4), it may seem unlikely that the degree of defect in insulin action and in glycogen synthase activation demonstrated in the relatives in this study is by itself sufficient to cause frank NIDDM. Therefore, other (secondary?) factors such as elevated plasma NEFA concentrations and/or obesity (4) may be involved in further unmasking the defect in activation of glycogen synthase in the group who develops NIDDM, thereby clearly separating this group from the group who will escape development of NIDDM. Alternatively, the implication of the considerable overlap in insulin action and in the activation in glycogen synthase activity between the groups could be that, in addition to the familiarly determined defect in insulin action, a certain degree of a (genetically determined ?) defect in insulin secretion may be required for the development of frank NIDDM.

The present study does not answer the question of whether the defect glycogen synthase activation in the relatives is due to a defect in the enzyme per se, or whether it may be secondary to, and the effect of, other potential defects in the cellular insulin signal transduction before the activation of glycogen synthase. The molecular mechanism by which insulin stimulates glycogen synthase is complicated and not fully understood (50). Initially, insulin binds to the receptor (alpha subunit) on the cell membrane surface. The transmembrane part of the receptor (beta subunit) is a tyrosine kinase (insulin receptor tyrosine kinase), which after insulin stimulation is autophosphorylated, and may initiate a cascade of phosphorylation-dephosphorylation reactions of other proteins. Eventually, this cascade reaction produces phosphorylation, and subsequently, activation of the specific glycogen synthase phosphatase (protein phosphatase one or PP1) that is responsible for the dephosphorylation and activation of glycogen synthase (50). A defect in in vivo insulin activation of the insulin receptor tyrosine kinase in skeletal muscles was recently reported in Pima Indians with NIDDM (51), indicating that this could explain some of the insulin resistance in this syndrome. On the other hand, the same study indicated that the site of insulin resistance in nondiabetic Pima Indians was located distal to the tyrosine kinase (51). Furthermore, it has been demonstrated that the defect tyrosine kinase activity in adipocytes from NIDDM patients can be completely reversed after intensive hypocaloric treatment (52). Thus, a defect insulin receptor kinase activity may not explain the defect insulin stimulation of muscle glycogen synthase activity in the nondiabetic relatives in this study. However, other defects in the insulin signal system could have caused the defect, as for example, reduced rates of glycogen synthase phosphatase activities (53), and/or a defective insulin-induced inhibition of cAMP-dependent protein kinase in skeletal muscle (54). Finally, abnormalities in inositol metabolism (55) or in as yet unidentified insulin signal transduction systems could theoretically contribute to the observed impairment of glycogen synthase activation in the relatives.

Despite insulin resistance, the relatives in the present study had normal fasting plasma glucose concentrations, normal levels of glycosylated hemoglobin, and only marginally elevated plasma glucose concentrations during the oral glucose tolerance tests. This can be explained by the compensatory hypersecretion of insulin from the pancreatic beta-cell in the relatives, enabling these subjects to overcome the insulin resistance. In fact, hyperinsulinemia has previously been demonstrated in nondiabetic relatives to NIDDM patients in the fasting state $(18,56,57)$, after an oral glucose load $(56,57)$, after an intravenous glucose infusion (second phase insulin response) (18), and was demonstrated in the relatives in the present study both in the fasting state and in response to an oral glucose load. The finding of hyperinsulinemia, in spite of normal plasma glucose concentrations, also indicates normal beta-cell function in the relatives, which suggests that the defect insulin secretion in NIDDM (58) is not an early (primary) defect.

In conclusion, our study demonstrates that insulin resistance is present in young and carefully sex and weight matched nonobese Caucasian first-degree relatives of patients with NIDDM, decades before these subjects may develop frank diabetes. The insulin resistance is located to the glucose storage pathway, and is probably due to an impaired activation of the enzyme glycogen synthase in skeletal muscles. This defect could be a primary, and perhaps genetically determined, defect that contributes to the development of non-insulin-dependent diabetes mellitus.

\section{Acknowledgments}

The authors would like to acknowledge the expert technical assistance of Karin Dyregaard, Henriette Vorup, Bente Hansen, Bente Mottlau, and Annemette Forman. We are grateful to Dr. Frank Alford for critically reviewing the manuscript. Dr. E. A. Richter is acknowledged for providing laboratory facilities.

The study was supported by grants from the Danish Medical Research Council, the Danish Diabetes Association, the Nordisk Insulin Foundation, and from the Clinical Research Institute, Odense University Hospital.

\section{References}

1. DeFronzo, R., D. Deibert, R. Hendler, P. Felig, and V. Soman. 1979. Insulin sensitivity and insulin binding to monocytes in maturity-onset diabetes. $J$. Clin. Invest. 63:939-946.

2. Kolterman, O., R. Gray, J. Griffin, P. Bernstein, J. Insel, J. Scarlett, and J. Olefsky. 1981. Receptor and postreceptor defects contribute to the insulin resistance in non-insulin dependent diabetes mellitus. J. Clin. Invest. 68:957-969.

3. DeFronzo, R., R. Gunnarson, O. Björkman, M. Olsson, and J. Wahren. 1985. Effect of insulin on peripheral and splanchnic glucose metabolism in noninsulin dependent (type 2) diabetes mellitus. J. Clin. Invest. 76:149-155.

4. Damsbo, P., A. Vaag, O. Hother-Nielsen, and H. Beck-Nielsen. 1991. Reduced glycogen synthase activity in skeletal muscle from obese patients with and without Type 2 (non-insulin-dependent) diabetes mellitus. Diabetologia. 34:239-245.

5. Kelley, D. E., and L. J. Mandarino. 1990. Hyperglycemia normalizes insulin-stimulated skeletal muscle glucose oxidation and storage in non-insulin-dependent diabetes mellitus. J. Clin. Invest. 86:1999-2007.

6. Meyer, H. U., B. Curchod, P. Maeder, E. Pahud, E. Jequier, and J. P. Felber. 1980. Modifications of glucose storage and oxidation in nonobese diabetics, measured by continuous indirect calorimetry. Diabetes. 29:752-756. 
7. Boden, G., T. K. Ray, R. H. Smith, and O. E. Owen. 1983. Carbohydrate oxidation and storage rates in obese non-insulin dependent diabetic patients. Effect of improving glycaemic control. Diabetes. 32:982-987.

8. Golay, A., R. A. DeFronzo, E. Ferrannini, D. C. Simonson, D. Thorin, K. Acheson, D. Thiebaud, B. Curchod, E. Jequier, and J. P. Felber. 1988. Oxidative and non-oxidative glucose metabolism in non-obese Type 2 (non-insulin dependent) diabetic patients. Diabetologia. 31:585-591.

9. Schulman, D., D. L. Rothman, T. Jue, P. Stein, R. A. DeFronzo, and R. G. Schulman. 1990. Quantitation of muscle glycogen synthesis in normal subjects and subjects with non-insulin dependent diabetes by ${ }^{13} \mathrm{C}$-nuclear magnetic resonance spectroscopy. $N$. Engl. J. Med. 322:223-228.

10. Leloir, L. F., J. M. Olavaria, S. H. Goldenberg, and H. Carminatti. 1959. Biosynthesis of glycogen from uridine diphosphate glucose. Arch. Biochem. Biophys. 81:508-520.

11. Mandarino, L., K. Wright, L. Verity, J. Nichols, J. Bell, O. Kolterman, and $H$. Beck-Nielsen. 1987. Effects of insulin infusion on human skeletal muscle pyruvate dehydrogenase, phosphofructokinase, and glycogen synthase. J. Clin. Invest. 80:655-663.

12. Villar-Palasi, C., and J. Larner. 1960. Insulin-mediated effect on the activity of UDPG-glycogen transglucosylase of muscle. Biochim. Biophys. Acta. 81:508-520.

13. Bogardus, C., S. Lillioja, K. Stone, and D. Mott. 1984. Correlation between muscle glycogen synthase activity and in vivo insulin action in man. $J$. Clin. Invest. 73:1185-1190.

14. Johnson, A. B., M. Argyraki, J. C. Thow, D. Broughton, I. R. Jones, and R. Taylor. 1990. Effects of intensive dietary treatment on insulin-stimulated skeletal muscle glycogen synthase activation and insulin secretion in newly presenting type 2 diabetic patients. Diabetic Medicine. 7:420-428.

15. Thorburn, A. W., B. Gumbiner, F. Bulacan, G. Brechtel, and R. R. Henry. 1991. Multiple defects in muscle glycogen synthase activity contribute to reduced glycogen synthesis in non-insulin dependent diabetes mellitus. J. Clin. Invest. 87:489-495.

16. Lillioja, S., D. M. Mott, B. V. Howard, P. H. Bennett, H. Yki-Järvinen, D. Freymond, B. L. Nyomba, F. Zurlo, B. Swinburn, and C. Bogardus. 1988. Impaired glucose tolerance as a disorder of insulin action. Longitudinal and crosssectional studies in Pima indians. N. Engl. J. Med. 318:1217-1225.

17. Eriksson, J., A. Franssila-Kallunki, A. Ekstrand, C. Saloranta, E. Widén, C. Schalin, and L. Groop. 1989. Early metabolic defects in persons at increased risk for non-insulin-dependent diabetes mellitus. N. Engl. J. Med. 321:337-343.

18. Warram, J. H., B. C. Martin, A. S. Krolewski, J. S. Soeldner, and C. R. Kahn. 1990. Slow glucose removal rate and hyperinsulinemia precede the development of Type 2 diabetes in the offspring of diabetic patients. Ann. Intern. Med. 113:909-915.

19. McGuire, E. A. H., J. H. Helderman, J. D. Tobin, R. Andres, and M. Berman. 1976. Effects of arterial versus venous sampling on analysis of glucose kinetics in man. J. Appl. Physiol. 55:628-634.

20. Frayn, K. N. 1983. Calculation of substrate oxidation rates in vivo from gaseous exchange. J. Appl. Physiol. 55:628-634.

21. Ferrannini, E. 1983. The theoretical basis of indirect calorimetry: a review. Metab. Clin. Exp. 37:287-301.

22. Tappy, L., O. E. Owen, and G. Boden. 1988. Effect of hyperinsulinemia on urea pool size and substrate oxidation rates. Diabetes. 37:1212-1216.

23. Steele, R. 1959. Influence of glucose loading and of injected insulin on hepatic glucose output. Ann. NY Acad. Sci. 82:420-430.

24. Cowan, J. S., and S. Hetenyi. 1971. Glucoregulatory responses in normal and diabetic dogs recorded by-a new tracer method. Metab. Clin. Exp. 20:360372.

25. Cobelli, C., A. Mari, and E. Ferrannini. 1987. Non-steady state: error analysis of Steele's model and development for glucose kinetics. Am. J. Physiol. 252:E679-689.

26. Bergman, R. N., I. D. Hope, Y. J. Yang, R. M. Watanabe, M. A. Meador, J. H. Youn, and M. Ader. 1989. Assessment of insulin sensitivity in vivo: a critical review. Diabetes Metab. Rev. 5:411-429.

27. Lukaski, H. C., P. E. Johnson, W. W. Bolonchuk, and G. I. Lykken. 1985. Assessment of fat-free mass using bioelectrical impedance measurements of the human body. Am. J. Clin. Nutr. 41:810-817.

28. Lowry, O. H., and J. V. Passoneau. 1972. A Flexible System of Enzymatic Analysis. Academic Press, Inc., New York.

29. Sjøgaard, G., R. P. Adams, and B. Saltin. 1985. Water and ion shifts in skeletal muscle of humans with intense dynamic knee extension. Am. J. Physiol. 248 (Regulatory Integrative Comp. Physiol. 17):R190-R 196.

30. Sjøgaard, G., and B. Saltin. 1982. Extra- and intracellular water spaces in muscles in man at rest and with dynamic exercise. Am. J. Physiol. 243 (Regulatory Integrative Comp. Physiol. 12):R271-R280.

31. Thomas, J., K. Schlender, and J. Larner. 1968. A rapid filter paper assay for UDP-glucose-glycogen glucosyltransferase, including an improved biosynthesis of UDP- ${ }^{14} \mathrm{C}$-glucose. Anal. Biochem. 25:486-499.
32. Lowry, O. H., N. J. Rosebrough, A. L. Farr, and R. J. Randall. 1951. Protein measurements with Folin phenol reagent. J. Biol. Chem. 193:265-272.

33. Andersen, I., and S. Hannibal. 1983. Analytical and economical optimization of a glucose method with immobilized enzymes. J. Automatic Chem. 5:188192.

34. Hother-Nielsen, O., and H. Beck-Nielsen. 1990. On determination of basal glucose production rate in patients with Type 2 (non-insulin dependent) diabetes using primed-continuous $3-{ }^{3} \mathrm{H}$-glucose infusion. Diabetologia. 33:603610.

35. Heding, L. G. 1972. Determination of total serum insulin (IRI) in insulintreated diabetic patients. Diabetologia. 8:260-266.

36. Heding, L. G. 1975. Radioimmunological determination of human Cpeptide in serum. Diabetologia. 11:541-548.

37. Itaya, K., and U. Michio. 1965. Colorimetric determination of free fatty acids in biological fluids. J. Lipid Res. 6:16-20.

38. Mortensen, H. B. 1980. Quantitative determination of hemoglobin $A_{t c}$ by thin layer isoelectric focusing. J. Chromatogr. 182:325-333.

39. Downie, N. M., and R. W. Heath. 1970. Basic Statistical Methods. 3rd ed. Harper International Edition, New York, Evanston, and London. 122-123.

40. Kirk, R. L., S. W. Serjeantson, H. King, and P. Zimmet. 1985. The genetic epidemiology of diabetes mellitus. Prog. Clin. Biol. Res. 194:119-146.

41. Barnett, A. H., C. Eff, D. G. Leslie, and D. A. Pyke. 1981. Diabetes in identical twins. Diabetologia. 20:87-93.

42. Newman, B., J. V. Selby, M. C. King, C. Siemenda, R. Fabsitz, and G. D. Friedman. 1987. Concordance for Type 2 (non-insulin-dependent) diabetes mellitus in male twins. Diabetologia. 30:763-768.

43. Lillioja, S., D. M. Mott, J. K. Zawadzki, A. A. Young, W. G. H. Abbott, W. C. Knowler, P. H. Bennett, P. Moll, and C. Bogardus. 1987. In vivo insulin action is familial characteristic in nondiabetic Pima indians. Diabetes. 36:13291335

44. Bodkin, N. L., B. L. Metzger, and B. C. Hansen. 1989. Hepatic glucose production and insulin sensitivity preceding diabetes in monkeys. Am. J. Physiol. 256 (E-ndocrinol. Metab. 19):E676-E681.

45. Greenfield, M., O. Kolterman, J. Olefsky, and G. M. Reaven. 1980. Mechanism of hypertriglyceridaemia in patients with fasting hyperglycaemia. Diabetologia. 18:441-446.

46. Reaven, G. M., and M. S. Greenfield. 1981. Diabetic hypertriglyceridaemia: evidence for three clinical syndromes. Diabetes. 30:66-75.

47. Randle, P. J., P. B. Garland, C. N. Hales, and E. A. Newsholme. 1963. The glucose fatty-acid cycle: its role in insulin sensitivity and the metabolic disturbances of diabetes mellitus. Lancet i:785-789.

48. Felber, J. P., E. Ferrannini, A. Golay, H. U. Meyer, D. Thiebaud, B. Curchod, E. Maeder, E. Jéquier, and R. A. DeFronzo. 1987. Role of lipid oxidation in pathogenesis of insulin resistance of obesity and type 2 diabetes. Diabetes. 36:1341-1350.

49. Vaag, A., P. Skött, P. Damsbo, M.-A. Gall, E. A. Richter, and H. BeckNielsen. 1991. Effect of the antilipolytic nicotinic acid analogue Acipimox on whole body and skeletal muscle glucose metabolism in patients with non-insulindependent diabetes mellitus. J. Clin. Invest. 88:1282-1290.

50. Dent, P., A. Lavoinne, S. Nakielny, F. B. Caudwell, P. Watt, and P. Cohen. 1990. The molecular mechanism by which insulin stimulates glycogen synthesis in mammalian muscle. Nature (Lond.). 348:302-308.

51. Nyomba, B. L., V. M. Ossowski, C. Bogardus, and D. M. Mott. 1990 Insulin-sensitive tyrosine kinase: Relationship with in vivo insulin action in humans. Am. J. Physiol. 258 (Endocrinol. Metab. 21):E964-E974.

52. Freidenberg, G. R., D. Reichart, J. M. Olefsky, and R. R. Henry. 1988 Reversability of defective adipocyte insulin receptor kinase activity in non-insulin-dependent diabetes mellitus. J. Clin. Invest. 82:1398-1406.

53. Kida, Y., A. D. Puente, C. Bogardus, and D. M. Mott. 1990. Insulin resistance is associated with reduced fasting and insulin-stimulated glycogen synthase phosphatase activity in human skeletal muscle. J. Clin. Invest. 85:476-481.

54. Kida, Y., B. L. Nyomba, C. Bogardus, and D. M. Mott. 1990. Defective insulin response of cyclic adenosine monophosphate protein kinase in insulin resistant humans. J. Clin. Invest. 87:673-679.

55. Kennington, A. S., C. R. Hill, J. C. Craig, C. Bogardus, I. Raz, H. K. Ortmeyer, B. C. Hansen, G. Romero, and J. Larner. 1990. Low urinary chiro-inositol excretion in non-insulin-dependent diabetes mellitus. N. Engl. J. Med. 323:373-378.

56. Leslie, R. D. G., H. P. Volksman, M. Poncher, I. Hanning, H. Ørskov, and K. G. M. M. Alberti. 1986. Metabolic abnormalities in children of non-insulin dependent diabetics. Br. Med. J. 293:840-842.

57. Haffner, S. M., M. P. Stern, H. P. Hazuda, B. D. Mitchell, and J. K Patterson. 1988. Increased insulin concentrations in nondiabetic offspring of diabetic parents. N. Engl. J. Med. 319:1297-1301.

58. Porte, D. 1991. Beta-cells in Type 2 diabetes mellitus (Banting lecture 1990). Diabetes. 40:166-180 